\title{
Sequential injection flow system with improved sample throughput: determination of glycerol and ethanol in wines
}

\author{
Marcela A. Segundo, António O.S.S. Rangel* \\ Escola Superior de Biotecnologia, Universidade Católica Portuguesa, Rua Dr. António Bernardino de Almeida, 4200-072 Porto, Portugal
}

Keywords: Glycerol; Ethanol; Wine; Sequential injection; Glycerol dehydrogenase; Alcohol dehydrogenase; Port wine

\begin{abstract}
The performance of sequential injection (SI) systems has often been criticized for its low sampling frequency. The present work describes a SI system where an injection valve and an additional pump were incorporated to enhance sample throughput rate. The proposed system was applied to the enzymatic determination of glycerol and ethanol in wines, using spectrophotometric detection and immobilized glycerol and alcohol dehydrogenases. The method proposed was applied to the determination of ethanol between 0.10 and $0.50 \%(\mathrm{v} / \mathrm{v})$ and glycerol between 0.03 and $0.30 \mathrm{~g}^{-1}$. These ranges were appropriate for determination in table and port wines, since samples were diluted 50 times before introduction into the system. The results obtained from 15 wine samples were statistically comparable to those obtained by the reference methods, with good repeatability (R.S.D. $<3.4 \%, n=10$ ). The sampling rate was $22.5 \mathrm{~h}^{-1}$, corresponding to 45 determinations per hour. This way, the time required for each determination was decreased by $30 \%$ when compared to a conventional SI system.
\end{abstract}

\section{Introduction}

Since its introduction in 1990 by Ruzicka and Marshall [1], sequential injection analysis (SIA) has been successfully applied to perform several determinations, some of them cumbersome, involving gas diffusion [2], dialysis [3], extraction or preconcentration [4]. Simplicity is one of the main features attributed to a SI system, conceived as a single manifold, composed of a single pump, one valve and a single channel [5]. Flexibility is another attribute of this system, as the same manifold can be adapted to perform different assays by changing parameters in the con-

\footnotetext{
* Corresponding author. Tel.: +351-22-5580064; fax: +351-22-5090351.

E-mail address: rangel@esb.ucp.pt (A.O.S.S. Rangel).
}

trolling software $[4,6]$. These two characteristics and reduction of reagent consumption make SIA an attractive alternative to flow injection analysis (FIA) [7]. A lower sampling frequency is the major disadvantage of SIA when compared to other flow techniques $[4,6]$.

In this work, a SIA system with an increased throughput rate is presented; this was achieved by coupling an injection valve and an additional pump. Injection valves have already been used in SIA systems for different purposes. For instance, they were used to solve flowing-out problems in gas diffusion units [8,9] and they have been applied in systems where sequential injection-wetting film extraction were performed [10-13]. Recently, two injection valves were incorporated into a manifold for renewable column packing and disposal, which was applied in sorbent extraction separations of radionuclides 


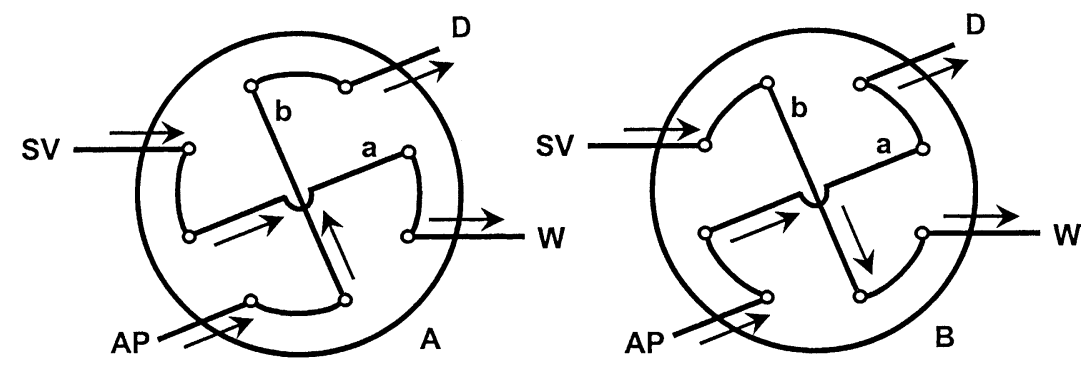

Fig. 1. Injection valve configuration including two loops ( $a$ and b). The arrows indicate the flow direction. SV: selection valve; AP: auxiliary pump; D: detection system; W: waste; A, B: injection valve positions; a, b: loops.

[14]. The inclusion of an injection valve to enhance throughput has only been reported once, Guzman and Compton [15] used it to switch between a peristaltic and a piston pump to deliver solutions through the holding coil. Effective use of time was achieved when the system was cleaned up by use of the peristaltic pump while the piston pump was refilled.

The main idea behind the present work was to develop a system where sample and reagents were aspirated through a selection valve as in SIA, but the stacked zones formed in the holding coil were sent to fill the loop of an injection valve, the loop content was then injected into a carrier stream and directed to the detector, as occurs in FIA. Therefore, the eight-port injection valve was incorporated in such a way that two loops were formed as depicted in Fig. 1. After sequential aspiration of sample and reagent into the holding coil, the stacked zones were sent to one of the loops while the other was swept by carrier from an auxiliary pump, pushing its content to the detector. After switching the position of the injection valve, the first loop content was flushed to the detector while the other loop was filled with another segment of sample and reagent.

To demonstrate the feasibility of the proposed system, we applied it to the determination of glycerol and ethanol in wines. The method was based on the spectrophotometric determination of NADH at $340 \mathrm{~nm}$ after oxidation of glycerol and ethanol in the presence of $\mathrm{NAD}^{+}$by action of glycerol dehydrogenase and alcohol dehydrogenase, respectively. This methodology was chosen for two reasons. First, as the reactions yield the same product, the same wavelength could be applied. Secondly, the enzymes could be immobilized, packed in a reactor and easily adapted to each loop of the injection valve.

\section{Experimental section}

\subsection{Reagents and solutions}

All chemicals used were of analytical reagent grade with no further purification, and deionized water with a specific conductance $<0.1 \mu \mathrm{S} \mathrm{cm}^{-1}$ was used throughout.

Alcohol dehydrogenase (ADH, $300 \mathrm{U} \mathrm{mg}^{-1}$, EC 1.1.1.1, ref. 127540), glycerol dehydrogenase (GlyDH, $25 \mathrm{U} \mathrm{mg}^{-1}$, EC 1.1.1.6, ref. 258555) and $\mathrm{NAD}^{+}$(grade III, 90\%, ref. 710113) were purchased from Boehringer (Manheim, Germany). Aminopropyl glass (average pore size: $500 \AA$; 200-400 mesh, ref. G-4643) was obtained from Sigma (St. Louis, MO).

For immobilization of enzymes, a $0.1 \mathrm{moll}^{-1}$ potassium dihydrogenphosphate buffer $(\mathrm{pH}$ 7.0) and a $2.5 \%$ glutaraldehyde solution (Merck, Schuchardt, Germany) in buffer were prepared.

For the flow system, the carbonate buffer carrier solution was prepared by dissolving $5.0 \mathrm{~g}$ of potassium hydrogencarbonate in 11 of water and adjusting the $\mathrm{pH}$ to 9.5 by dropwise addition of concentrated potassium hydroxide solution. An aqueous solution of $20 \mathrm{mmoll}^{-1} \mathrm{NAD}^{+}$was prepared daily.

Mixed standard solutions in the concentration range $0.030-0.300 \mathrm{~g}^{-1}$ glycerol and $0.100-0.500 \%$ $(\mathrm{v} / \mathrm{v})$ ethanol were prepared from pure glycerol and ethanol. The wine samples were diluted 50-fold in water before introduction into the system.

\subsection{Enzyme immobilization and reactor preparation}

Suspended GlyDH (4.0 mg) and ADH (15 mg) were immobilized separately on $0.5 \mathrm{~g}$ of aminopropyl 
derivatised controlled pore glass following the procedure described by Masoom and Townshend [16] with some modifications [17]. The immobilized enzymes were stored wet in phosphate buffer at $4{ }^{\circ} \mathrm{C}$ in a tightly closed tube and remained stable for about 2 months. The reactors were prepared by filling a piece of Gilson (Villiers-le-Bel, France) PVC pumping tube (i.d. $3.5 \mathrm{~mm}$ ) using a syringe containing immobilized enzyme dispersed in phosphate buffer. Ordinary dishwashing foam was placed at both ends of the reactor to entrap the controlled pore glass. When not in use, the reactors were kept at $4{ }^{\circ} \mathrm{C}$ in phosphate buffer at pH 7.0.

\subsection{Apparatus}

Two Gilson Minipuls 3 peristaltic pumps, equipped with Gilson PVC pumping tubes propelled the solutions. One of the pumps was connected to the central channel of an eight-port electrically actuated selection valve (Valco VICI C25-3118E, Schenkon, Switzerland). The other pump was connected to one of the ports of an eight-port injection valve (Valco VICI C12-3118E).

A Unicam (Cambridge, UK) 8625 UV-VIS spectrophotometer equipped with a Helma (Müllheim, Balden, Germany) 178.711QS flow-through cell (internal volume $30 \mu \mathrm{l}$ ) was used as the detection system and the wavelength was set at $340 \mathrm{~nm}$. The analytical signals were recorded in a Kipp and Zonen (Delft, The Netherlands) BD 111 strip chart recorder.

A 386 personal computer equipped with an Advantec (Taipei, Taiwan) PCL818L interface card, running software written in QuickBasic 4.5 (Microsoft), controlled the position of the valves and both the direction and speed of rotation on the peristaltic pump connected to the selection valve.

For the reference ethanol determination, a distillation apparatus and a Denis Alcoholmeter (Arnouville, France) were used, as described for the usual methods of the OIV [18]. For the reference glycerol determination, the spectrophotometric measurements were carried out at $340 \mathrm{~nm}$ using the Unicam spectrophotometer.

\subsection{Manifold and procedure}

The system components were arranged as shown schematically in Fig. 2. The connections were made from Omnifit (Cambridge, UK) PTFE tubing $(0.8 \mathrm{~mm}$ i.d.) with Gilson end-fittings and connectors. All connections were $20 \mathrm{~cm}$ long, except for the connection between the injection valve and detector $(36 \mathrm{~cm})$ and the tubing placed before the reactors. In this case, their length was $60 \mathrm{~cm}$, three times longer than the tubing connecting the two valves. In this way, effective washing of this last connection was achieved as it was possible to send three times its volume through the

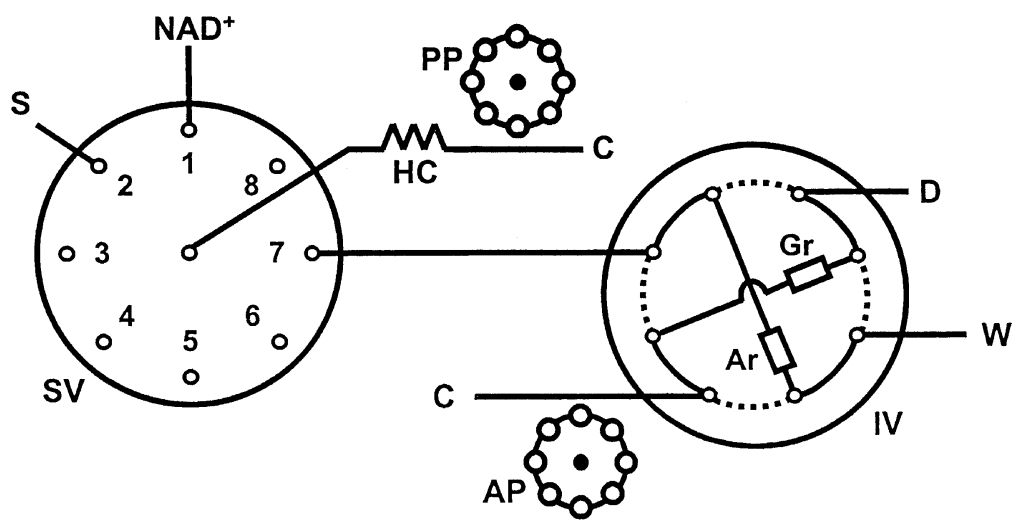

Fig. 2. Manifold for the determination of glycerol and ethanol in wines. SV: selection valve; IV: injection valve; PP: peristaltic pump; AP: auxiliary pump; HC: holding coil; $\mathrm{D}$ : detection system; $\mathrm{S}$ : sample or standard; $\mathrm{NAD}^{+}=20 \mathrm{mmoll}^{-1} \mathrm{NAD}^{+}$solution; $\mathrm{C}=0.05$ moll $1^{-1}$ hydrogencarbonate buffer $(\mathrm{pH}=9.5)$; $\mathrm{W}$ : waste; $\mathrm{Gr}$ : glycerol dehydrogenase reactor; Ar: alcohol dehydrogenase reactor. 
Table 1

Protocol sequence for determination of glycerol and ethanol in wines ${ }^{\mathrm{a}}$

\begin{tabular}{|c|c|c|c|c|}
\hline \multicolumn{2}{|c|}{ Selection valve } & \multirow[t]{2}{*}{ Operation time (s) } & \multicolumn{2}{|c|}{ Injection valve } \\
\hline Position & Description & & Position & Description \\
\hline 1 & Aspiration of $45 \mu 1$ of $\mathrm{NAD}^{+}$solution & 11.1 & A & Washing of ADH reactor \\
\hline 2 & Aspiration of $45 \mu \mathrm{l}$ of sample/standard solution & 11.1 & A & Washing of $\mathrm{ADH}$ reactor \\
\hline 7 & Propulsion of $\mathrm{HC}$ content towards the GlyDH loop & 25.0 & A & Washing of $\mathrm{ADH}$ reactor \\
\hline 7 & - & 30.0 & $\mathrm{~B}$ & Detection of glycerol peak \\
\hline 1 & Aspiration of $15 \mu \mathrm{l}$ of $\mathrm{NAD}^{+}$solution & 3.7 & $\mathrm{~B}$ & Washing of GlyDH reactor \\
\hline 2 & Aspiration of $15 \mu \mathrm{l}$ of sample/standard solution & 3.7 & $\mathrm{~B}$ & Washing of GlyDH reactor \\
\hline 7 & Propulsion of HC content towards the ADH loop & 30.0 & $\mathrm{~B}$ & Washing of GlyDH reactor \\
\hline 7 & - & 30.0 & $\mathrm{~A}$ & Detection of ethanol peak \\
\hline
\end{tabular}

${ }^{\mathrm{a}} \mathrm{HC}$ : holding coil.

two loops [6], without pushing the $\mathrm{NAD}^{+}$plus sample segment to waste.

The protocol of flow and timing sequence for the determination of glycerol and ethanol in wines is listed in Table 1.

First, $\mathrm{NAD}^{+}$and sample were sequentially aspirated into the holding coil, after flow reversal, the stacked zones were sent through the loop where the GlyDH reactor was placed. During these operations, the loop containing the ADH reactor was continuously washed with carrier propelled by the auxiliary pump. Subsequently, the position of the injection valve was changed and the carrier from the auxiliary pump flowed through the GlyDH reactor, pushing the NADH formed towards the detector. After a certain period of time, the previous operations were repeated, but this time the stacked zones were sent to the ADH reactor, while the carrier from the auxiliary pump washed the GlyDH reactor. The position of the injection valve was then switched, and the NADH formed in the $\mathrm{ADH}$ reactor was measured.

The flow rate used to aspirate both $\mathrm{NAD}^{+}$and sample/standards was $0.24 \mathrm{ml} \mathrm{min}^{-1}$. The other steps were performed at $1.0 \mathrm{ml} \mathrm{min}^{-1}$.

\subsection{Reference methods}

The reference method for glycerol in wine was performed using the test kit "Glycerol UV method for the determination of glycerol in foodstuffs and other materials" from Boehringer (ref. 148270). The measurements were done after the procedure "Determination of glycerol in wine" which is described in the test kit package. Prior to the analysis, the samples were diluted 50-fold with deionized water. The reference method for ethanol was performed by the usual hydrometric method of the OIV [18], based on the specific gravity of the wine distillate.

\section{Results and discussion}

\subsection{Development of the sequential injection system}

The following studies were performed using a ADH reactor $25 \mathrm{~mm}$ long and a GlyDH reactor $30 \mathrm{~mm}$ long, except when indicated otherwise.

\subsubsection{Composition of carrier buffer}

Both hydrogencarbonate concentration and $\mathrm{pH}$ value were evaluated. Hydrogencarbonate concentration was varied between 0.005 and $0.2 \mathrm{moll}^{-1}$, keeping the $\mathrm{pH}$ at 9.5. With the GlyDH reactor placed in loop a (Fig. 1), $30 \mu \mathrm{l}$ of $10 \mathrm{mmol}^{-1} \mathrm{NAD}^{+}$plus the same amount of $0.500 \mathrm{gl}^{-1}$ standard were injected. Up to $0.050 \mathrm{moll}^{-1} \mathrm{HCO}_{3}{ }^{-}$, the absorbance increased, for higher concentrations, the values were about the same. Keeping the original hydrogencarbonate concentration at $0.050 \mathrm{moll}^{-1}$, the $\mathrm{pH}$ was changed between 8.5 and 10.5. This study was performed separately for each reactor, placed in loop a. The same procedure was employed for the GlyDH reactor; for the $\mathrm{ADH}$ reactor, the volumes used were $15 \mu \mathrm{l}$ of $10 \mathrm{mmol}^{-1} \mathrm{NAD}^{+}$plus $15 \mu \mathrm{l}$ of $0.250 \%$ ethanol standard. As previously reported [19], the signal increased with tested $\mathrm{pH}$ values for both enzymes. 
However, when consecutive injections were performed at $\mathrm{pH} 10.0$, placing reactor $\mathrm{ADH}$ in loop $\mathrm{b}$ and GlyDH in loop a, the signal from the GlyDH reactor decreased by $30 \%$ after 35 injections, indicating poor enzyme stability; the signal from the ADH reactor decreased by only $4 \%$. As a compromise between enzyme stability and sensitivity, the $\mathrm{pH}$ chosen was 9.5 .

\subsection{2. $N A D^{+}$concentration}

The $\mathrm{NAD}^{+}$concentration was studied between 10 and $50 \mathrm{mmoll}^{-1}$; the GlyDH reactor was placed in loop a and the ADH reactor was placed in loop b. For the glycerol determination, $30 \mu \mathrm{l}$ of $\mathrm{NAD}^{+}$ plus $30 \mu \mathrm{l}$ of $0.500 \mathrm{~g} \mathrm{l}^{-1}$ glycerol standard were aspirated, for the ethanol determination, $15 \mu \mathrm{l}$ of $\mathrm{NAD}^{+}$ plus $15 \mu \mathrm{l}$ of $0.500 \%$ ethanol standard were used. For the glycerol determination, the signals obtained for $\mathrm{NAD}^{+}$concentration of 10,20 and $30 \mathrm{mmoll}^{-1}$ were 57, 81 and $90 \%$ of the signal obtained for the $50 \mathrm{mmoll}^{-1} \mathrm{NAD}^{+}$solution, respectively. For the ethanol determination, under the same conditions, the signals were 44,68 and $83 \%$ of the signal obtained for the $50 \mathrm{mmoll}^{-1} \mathrm{NAD}^{+}$solution. These results indicated that the signal increased with $\mathrm{NAD}^{+}$ concentration and this effect was more pronounced in the ethanol determination. Nevertheless, as $\mathrm{NAD}^{+}$is a rather expensive reagent, the concentration chosen was $20 \mathrm{mmol}^{-1}$ to minimize its consumption.

\subsubsection{Reactor placement in loops $a$ and $b$}

The flow direction was the same in loop a during loop filling and washing but, for loop b, it was reversed as depicted in Fig. 1. To evaluate the possible difference between the two positions, the ADH reactor was placed in each loop, $15 \mu$ l of $\mathrm{NAD}^{+}$and $15 \mu \mathrm{l}$ of standard (concentrations between 0.050 and $0.750 \%$ in ethanol) were sent through both loops, for $25 \mathrm{~s}$ in loop a and $30 \mathrm{~s}$ in loop $\mathrm{b}$. The signals obtained for loop b were about $40 \%$ of those obtained in loop a, probably owing to higher dispersion caused by the flow reversal occurred in loop b [8].

\subsubsection{Glycerol determination}

With the previous conditions set, the sensitivity for the glycerol determination was not satisfactory. To improve it, besides placing the GlyDH reactor in loop a, its length was increased to 40 and $50 \mathrm{~mm}$. Better sensitivity was achieved for both reactors when compared to the $30 \mathrm{~mm}$ reactor previously used, the length chosen was $40 \mathrm{~mm}$. With the same objective, the volumes were increased to $45 \mu \mathrm{l}$ and then to $60 \mu \mathrm{l}$. Higher signals were obtained for both volumes but interference from the wine matrix was observed when $60 \mu \mathrm{l}$ was used. Hence, the volumes chosen for $\mathrm{NAD}^{+}$and sample were $45 \mu \mathrm{l}$.

\subsubsection{Ethanol determination}

For this determination, the conditions previously described and the reactor placement in loop b provided the sensitivity and working range desired for the determination in wines, using the same dilution for both glycerol and ethanol determinations.

\subsection{Evaluation of the method and its application to wine samples}

The performance of the proposed system for the determination of both glycerol and ethanol in wines was evaluated regarding to application range, detection limit, sampling frequency, accuracy and repeatability. A recorder output corresponding to the injection of a set of standards and wine samples is presented in Fig. 3.

Two $\log$ (absorbance) versus log (concentration) graphs were plotted, defining one concentration range for each determination. The standards concentration varied between 0.030 and $0.300 \mathrm{~g}^{-1}$ of glycerol and between 0.100 and $0.500 \%(\mathrm{v} / \mathrm{v})$ of ethanol. These ranges were appropriate for determination in table and port wines, since its values multiplied by 50 yielded the values expected in such wines.

\subsubsection{Detection limit}

The detection limit was calculated as the concentration corresponding to the blank signal plus three times the standard deviation of 10 consecutive blank injections [20]. The blank signal was obtained by replacing the standards with water. For glycerol determination, the calculated detection limit was $0.008 \mathrm{gl}^{-1}$, for ethanol determination, the detection limit was $0.005 \%(\mathrm{v} / \mathrm{v})$.

\subsubsection{Sample throughput}

The time required for a complete analytical cycle is not merely the summation of the time required for each step performance. As the time spent for proper 


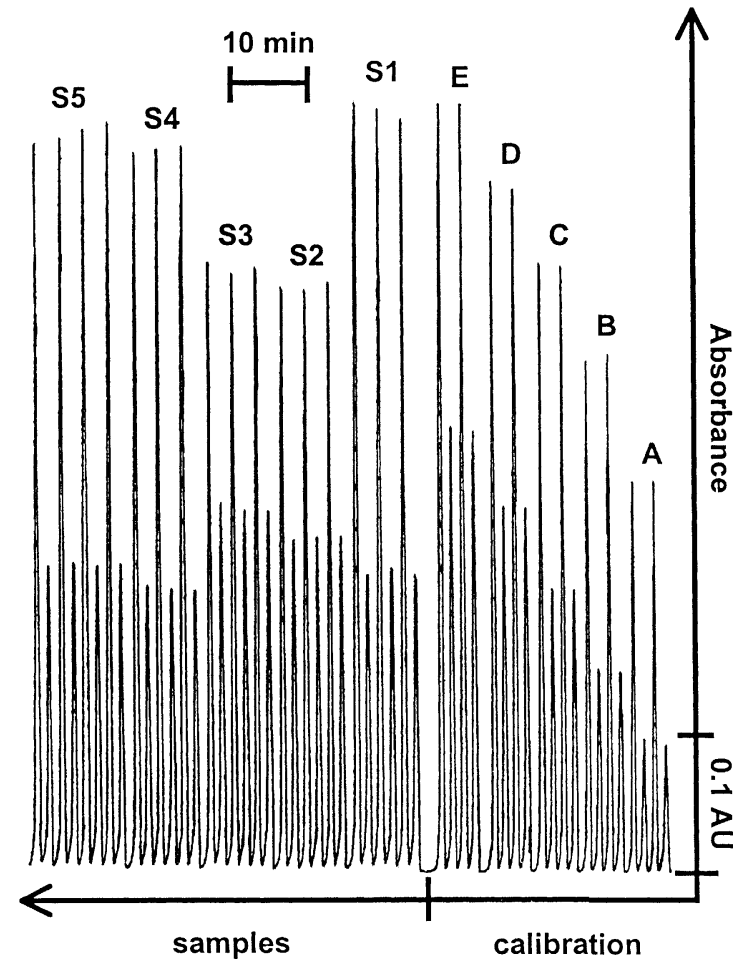

Fig. 3. Recorder output for the determination of glycerol and ethanol in wines $(\mathrm{Si})$. The first and second peaks correspond to glycerol and ethanol, respectively. The compositions of the mixed standards were: A: $0.030 \mathrm{gl}^{-1}$ and $0.100 \%(\mathrm{v} / \mathrm{v})$; B: $0.060 \mathrm{~g}^{-1}$ and $0.200 \%(\mathrm{v} / \mathrm{v}) ; \mathrm{C}: 0.120 \mathrm{~g}^{-1}$ and $0.300 \%(\mathrm{v} / \mathrm{v})$; D: $0.210 \mathrm{~g}^{-1}$ and $0.400 \%(\mathrm{v} / \mathrm{v})$; E: $0.300 \mathrm{gl}^{-1}$ and $0.500 \%(\mathrm{v} / \mathrm{v})$ glycerol and ethanol, respectively.

port selection in the selection valve must also be accounted, it took $160 \mathrm{~s}$ to complete an analytical cycle. Hence, the sampling rate was 22.5 samples per hour, corresponding to 45 determinations per hour.

\subsubsection{Comparison with the recommended procedure}

In order to evaluate the accuracy of the proposed system, 15 samples of table and port wines were analyzed. The results $\left(C_{\mathrm{p}}\right)$ were compared with those furnished by the recommended procedures $\left(C_{\mathrm{r}}\right)$ [18]; they are presented in Table 2 . The relative deviations between the recommended procedures and the proposed methodology were $<3.4 \%$ for the glycerol determination and $<3.7 \%$ for the ethanol determination.

For comparison purposes, a linear relationship $\left(C_{\mathrm{p}}=C_{0}+S C_{\mathrm{r}}\right)$ was established. The equation parameters, as well as the $95 \%$ confidence limits, are
Table 2

Results obtained by the proposed methodology $\left(C_{\mathrm{p}}\right)$ and by the reference methods $\left(C_{\mathrm{r}}\right)$ for the determination of glycerol $\left(\mathrm{g} \mathrm{l}^{-1}\right)$ and ethanol percentage (v/v), and the R.D. (\%) between the two methods $^{\mathrm{a}}$

\begin{tabular}{|c|c|c|c|c|c|c|}
\hline \multirow[t]{2}{*}{ Sample } & \multicolumn{3}{|c|}{ Glycerol } & \multicolumn{3}{|c|}{ Ethanol } \\
\hline & $C_{\mathrm{r}}$ & $C_{\mathrm{p}}$ & R.D. & $C_{\mathrm{r}}$ & $C_{\mathrm{p}}$ & R.D. \\
\hline 1 & 5.67 & 5.76 & 1.6 & 8.97 & 9.30 & 3.7 \\
\hline 2 & 5.77 & 5.80 & 0.5 & 10.4 & 10.4 & 0.0 \\
\hline 3 & 5.14 & 5.15 & 0.2 & 10.3 & 10.4 & 1.0 \\
\hline 4 & 6.17 & 6.17 & 0.0 & 10.9 & 10.5 & -3.7 \\
\hline 5 & 6.95 & 6.86 & -1.3 & 11.5 & 11.6 & 0.9 \\
\hline 6 & 6.64 & 6.48 & -2.4 & 10.5 & 10.4 & -1.0 \\
\hline 7 & 5.47 & 5.63 & 2.9 & 19.0 & 19.6 & 3.2 \\
\hline 8 & 5.16 & 5.29 & 2.5 & 19.7 & 19.9 & 1.0 \\
\hline 9 & 4.67 & 4.67 & 0.0 & 19.5 & 19.4 & -0.5 \\
\hline 10 & 5.34 & 5.22 & -2.2 & 19.8 & 19.9 & 0.5 \\
\hline 11 & 5.81 & 5.79 & -0.3 & 19.4 & 20.0 & 3.1 \\
\hline 12 & 5.63 & 5.75 & 2.1 & 19.8 & 20.2 & 2.0 \\
\hline 13 & 5.09 & 4.98 & -2.2 & 19.6 & 18.9 & -3.6 \\
\hline 14 & 5.28 & 5.10 & -3.4 & 18.4 & 18.1 & -1.6 \\
\hline 15 & 6.09 & 5.96 & -2.1 & 19.5 & 18.8 & -3.6 \\
\hline
\end{tabular}

a 1-3: White table wines; 4-6: red table wines; 7-15 port wines.

presented in Table 3. From these figures it is clear that the estimated slope and intercept do not differ significantly from the values 1 and 0 , respectively. Thus, there is no evidence for systematic differences between the two sets of results obtained by the proposed methodology and by the reference method, for both determinations [21].

Table 3

Parameters of the equation $C_{\mathrm{p}}=C_{0}+S C_{\mathrm{r}}$ for comparing the results obtained by the proposed methodology $\left(C_{\mathrm{p}}\right)$ and by the reference methods $\left(C_{\mathrm{r}}\right)$, and the values for R.S.D. $(\%),(n=10)$ for wine samples

\begin{tabular}{llll}
\hline & $C_{0}$ & $S$ & R.S.D. $^{\mathrm{a}}$ \\
\hline Glycerol & $0.267( \pm 0.593)^{\mathrm{b}}$ & $0.950( \pm 0.104)^{\mathrm{b}}$ & $1.6(5.75)$ \\
& & & $1.6(3.64)$ \\
& & & $1.1(7.80)$ \\
Ethanol & $0.024( \pm 0.870)^{\mathrm{b}}$ & $0.999( \pm 0.053)^{\mathrm{b}}$ & $1.8(20.2)$ \\
& & & $2.3(18.9)$ \\
& & & $3.4(11.1)$
\end{tabular}

${ }^{a}$ Measured for three wines, with the glycerol and ethanol concentrations $\left(\mathrm{gl}^{-1}\right.$ and percentage $(\mathrm{v} / \mathrm{v})$, respectively) given in parentheses.

${ }^{\mathrm{b}}$ The values in parentheses are the $95 \%$ confidence intervals. 


\subsubsection{Repeatability}

This was estimated by calculating the R.S.D. of results from 10 consecutive injections of wine samples. R.S.D were $<1.6 \%$ for the determination of glycerol and $<3.4 \%$ for the determination of ethanol (Table 3 ).

\subsubsection{Enzyme reactor stability}

The reactors were stable for about 2 weeks. During this time, 20 wine samples were analyzed, corresponding to more than 300 injections per reactor, including standard injections for system calibration.

\section{Conclusions}

The proposed system was able to simultaneously determine glycerol and ethanol in wines, with results comparable to those obtained by the reference methods, good repeatability, minimum sample treatment (dilution) and low $\mathrm{NAD}^{+}$consumption. As several ports of the selection valve are not used, on-line analysis could be implemented by connecting one of the ports to a bioreactor sampling line; the required sample dilution could also be performed in-line by coupling a mixing chamber to other available port.

Considering a conventional SIA system including a selection valve, a single pump, a holding coil connecting them and each enzymatic reactor placed in different ports of the selection valve, the operation steps to perform an analytical cycle would be, aspiration of $\mathrm{NAD}^{+}$, aspiration of sample, peak detection and reactor washing. Taking into account the operation time values presented in Table 1, the analytical cycle would take $114 \mathrm{~s}$ for each determination. Comparing the time required for both determinations ( $228 \mathrm{~s}$ ) with the value obtained for the proposed system, the time required for each determination has decreased about $30 \%$. Hence, the operation mode described can be regarded as an effective means to enhance the sample throughput rate, despite the increase in the cost of the apparatus for including another pump and an injection valve.

Concerning the ethanol determination, a SI system for its determination using the same methodology was previously described and applied to fermentation samples [22]. The proposed system requires less $\mathrm{NAD}^{+}$ $(0.3 \mu \mathrm{mol})$ for each ethanol determination when compared to the previous system $(0.5 \mu \mathrm{mol})$. Although the former system had a higher sampling rate $\left(26 \mathrm{~h}^{-1}\right)$, it took $140 \mathrm{~s}$ to perform only an ethanol determination against $160 \mathrm{~s}$ that our system requires to determine two different analytes.

It also should be emphasized that the proposed configuration is better when two different determinations are performed, one in each loop. As filling and washing of loop a occurred in the same direction and, for loop $b$, these operations were performed in opposite directions, the two loops are not equivalent.

\section{Acknowledgements}

The authors acknowledge the financial support from PRAXIS XXI/Agência de Inovação through Project P076-P31B-09/97-INSIA. M. A. Segundo thanks FCT for the Grant PRAXIS XXI BD/13648/97. The kind interest and helpful advice received from Ildikó Tóth are highly appreciated.

\section{References}

[1] J. Ruzicka, G.D. Marshall, Anal. Chim. Acta 237 (1990) 329.

[2] M.A. Segundo, A.O.S.S. Rangel, Anal. Chim. Acta 427 (2001) 279.

[3] A.N. Araújo, J.L.F.C. Lima, A.O.S.S. Rangel, M.A. Segundo, Talanta 52 (2000) 59.

[4] R.E. Taljaard, J.F. van Staden, Lab. Rob. Autom. 10 (1998) 325 .

[5] T. Gübeli, G.D. Christian, J. Ruzicka, Anal. Chem. 63 (1991) 2407.

[6] J. Ruzicka, T. Gübeli, Anal. Chem. 63 (1991) 1680.

[7] V. Cerdá, J.M. Estela, R. Forteza, A. Cladera, E. Becerra, P. Altimira, P. Sitjar, Talanta 50 (1999) 695.

[8] M.T. Oms, A. Cerdà, A. Cladera, V. Cerdà, R. Forteza, Anal. Chim. Acta 318 (1996) 251.

[9] M.T. Oms, A. Cerdà, V. Cerdà, Electroanalysis 8 (1996) 387.

[10] Y. Luo, R. Al-Othman, J. Ruzicka, G.D. Christian, Analyst 121 (1996) 601.

[11] S. Nakano, Y. Luo, D. Holman, J. Ruzicka, G.D. Christian, J. Flow Injection Anal. 13 (1996) 148.

[12] S. Nakano, Y. Luo, D.A. Holman, J. Ruzicka, G.D. Christian, Microchem. J. 55 (1997) 392.

[13] Y. Luo, S. Nakano, D.A. Holman, J. Ruzicka, G.D. Christian, Talanta 44 (1997) 1563.

[14] O. Egorov, M.J. O’Hara, J.W. Grate, J. Ruzicka, Anal. Chem. 71 (1999) 345.

[15] M. Guzman, B.J. Compton, Talanta 40 (1993) 1943.

[16] M. Masoom, A. Townshend, Anal. Chim. Acta 166 (1984) 111.

[17] A.O.S.S. Rangel, I.V. Tóth, Am. J. Enol. Vitic. 50 (1999) 259. 
[18] Office International de la Vigne et du Vin (OIV), Recueil des Méthodes Internationales d'Analyse des Vins et des Moûts, OIV, Bordeaux, 1990.

[19] I.L. Mattos, J.M. Fernandez-Romero, M.D. Luque de Castro, M. Valcárcel, Analyst 120 (1995) 179.
[20] International Union of Pure and Applied Chemistry (IUPAC) Anal. Chem. 48 (1976) 2294.

[21] J.C. Miller, J.N. Miller, Statistics for Analytical Chemistry, 3rd Edition, Ellis Horwood, Chichester, 1993 (Chapter 5).

[22] M. Hedenfalk, B. Mattiasson, Anal. Lett. 29 (1996) 1109. 